\title{
The interaction of concentrate intake and pasture development on rumen digestion characteristics
}

\author{
M Murphy, E Lindgren, N Van Gylswyk \\ Swedish University of Agricultural Science, Dept of Animal Management and Nutrition, \\ Kungsängen Research Centre, 75323 Uppsala, Sweden
}

Cows on pasture producing more than moderate amounts of milk (> 15-20 kg/d) require a supplementary feed. There is little experimental evidence on the effects of supplementary feeds on rumen metabolism. A two-factorial change-over experiment was designed to determine the effects of the nature of concentrates on rumen ecology.

The composition of the supplement SLOW was (in \% of DM) $24 \%$ rice, $23 \%$ beet fibre, $15 \%$ each of barley and oats, $14 \%$ rapeseed meal, $3 \%$ corn gluten meal, $3 \%$ brewer's dried grain plus vitamins and minerals (NDF content $=22 \%$ ). In the mixture FAST the rice, beet fibre, barley and oats were replaced by $35 \%$ wheat and $43 \%$ molassed beet pulp (NDF content $=20 \%$ ). Three rumen cannulated cows and 10 intact cows (average daily milk yield $25 \mathrm{~kg} \mathrm{ECM}$ ) in two groups with one cannulated cow per group were studied in a rotational grazing system beginning May 16 . There were 3 periods of 3 weeks. The third cannulated cow received no concentrates. Pasture intake (using chromium oxide as a marker), milk yield, rumen $\mathrm{pH}$ and VFA concentration were measured during the last week of each period as well as the passage rates. Other rumen parameters were measured during the second week.

There was a tendency for the cows ( 11 cows) when given the SLOW mix to eat less concentrate and more pasture compared with the FAST mix. There were no differences between treatments in any of the milk parameters.

The average NDF content (\% of DM) of the grass was 42,46 and $44 \%$ for periods 1,2 and 3 , respectively. The effective NDF degradation in the rumen of weekly composites of grass samples, measured with the nylon bag technique in grazing cows, varied from $49 \%$ in period 1 to $40 \%$ in period 2 to $42 \%$ in period 3. Effective protein degradation for the same periods was 72,70 and $59 \%$, respectively. Rumen ingesta weighed between 40 and $70 \mathrm{~kg}$ (wet weight). The weight increased from $10 \%$ of the live weight in period 1 to $11 \%$ and $12.5 \%$ for periods 2 and 3 , respectively for the cows given the concentrate mixes. For the cow consuming only pasture the values were $7 \%$, $8 \%$ and $9 \%$ for the same periods. The NDF content ( $\%$ of DM) of the rumen ingesta in that cow was 43,46 and $47 \%$ for periods 1,2 and 3 , respectively. For the cows eating the concentrate mix FAST the NDF content in the rumen ingesta was 41,41 and $33 \%$ for periods 1,2 and 3 , respectively. Corresponding values for cows eating SLOW were higher, 43,44 and $39 \%$, respectively.

The rumen propionate concentration of the cow consuming only pasture was $19-20 \%$ of the total VFA. The propionate proportion for the cows consuming the mixes was greater, $22-26 \%$. The higher content was more associated with cow than with mix.

Changes in the microbial composition changed with time on pasture. The dominating cellulolytic bacteria were Eubacterium cellulosolvens when FAST was fed and Butyrivibrio fibrisolvens when SLOW was fed.

The results suggest that there are differences in rumen metabolism, especially the NDF degradation, which can be related to the composition of the supplementary feed. This in turn may influence pasture intake. The mechanism must be more than a $\mathrm{pH}$ effect as the rumen $\mathrm{pH}$ is already low $(<5.8)$ in cows consuming only pasture. 